\title{
O PROCESSO DE INDUSTRIALIZAÇÃO NA REPÜBLICA NOVA
}

Adolar Koch **

\section{1 - APRESENTAÇÃO}

A idéia fundamental deste trabalho encontra o seu sentido na tentativa de diagnosticar o comportamento do processo de industrialização na República Nova. Essa busca envolve variáveis que foram delimitadas ao redor de uma visão de história e documentos (fontes) disponiveis.

Pretende-se dar uma visão da situação industrial gaúcha no seu processo de formação, destacando as dificuldades na sua origem, tanto ao nível de produção como de comercialização, e destacar, acima de tudo, que se trata de um setor econômico com enormes obstáculos no seu processo de desenvolvimento, gerados principalmente pela situação periférica gaúcha.

Considerando o Rio Grande do Sul como uma formação social específica dentro da formação social brasileira, pode-se colocar que a agropecuária, como setor de produção dominante internamente na época em questão, é dependente a nível nacional. A indústria corresponde a um setor de produção secundário ao lado deste, que, dentro da situação global de transição, de formação do capitalismo no Rio Grande do Sul, engatinha desde a fase de acumulação primitiva, visando a tornar-se o setor de produção dominante na formação social gaúcha. E importante lembrar que o setor agropecuário, mesmo sendo a atividade de produção dominante, não impõe ao Rio Grande do Sul as caracteristicas capitalistas plenamente configuradas. Pode-se ressaltar apenas que, desde a República Velha, os primeiros passos estão sendo dados para tanto.

Através da transferência de capitais do café para o setor industrial no final do século XX, na formação social especifica de São Paulo, já se tem uma expansão mais adiantada ao capitalismo no centro. Essa realidade fez com que o Rio Grande do Sul, com uma economia voltada basicamente para mercados, se afirmasse como periferia dentro do processo capitalista nacional. Aqui reside uma grande questão: a baixa capitalização do setor agropecuário de certa maneira não possibilitou transferências de capitais para a indústria. Tem-se no Rio Grande do Sul um momento de transição, que é o de procura do caminho capitalista. O próprio termo transição revela uma situação de vir a ser, o que significa, ao nível sócio-econômico, a elaboração, não de uma maneira linear, mas 
dialeticamente, de uma forma capitalista de formação social plenamente configurada.

Dentro da proposição de estabelecer um marco referencial para a análise do processo gaúcho de industrialização na República Nova, são fundamentais os elementos externos (capitalismo mundial e conjuntura nacional) como padrões de acumulação gaúchos,na dinâmica da totalidade. Esse posicionamento envolve uma visão de história, de buscar no processo de transformação das sociedades o seu caminho, no caso, o caminho da formação social gaúcha. Mesmo a análise sendo setorial, quer dizer, privilegiando um setor dentro do processo produtivo, a indústria, o sentido do mesmo não se dá em função de si mesmo, mas em função da totalidade da qual ela faz parte. Especificamente para o processo capitalista mundial, as industrializações nas periferias, por acontecerem em situações bem peculiares, comparadas ao primeiro processo de industrialização na Inglaterra, formam características bem diversas e cumprem função decisiva dentro do mesmo. Os elementos internos de acumulação igualmente fazem parte deste processo global capitalista, sendo os seus padrões de acumulação mais reflexo do capitalismo mundial do que uma luta pela industrialização. Esse posicionamento, e considerando a industrialização como a última etapa de transição para o capitalismo, compromete-nos com o processo capitalista da época e o mundo que nos cerca. Na busca das explicações dos nossos problemas sócio-econômicos, nada mais significativo que voltar para as raizes do capitalismo periférico dependente gaúcho.

$\mathrm{O}$ imperialismo atuou no estabelecimento de desigualdades regionais ao nivel de forças produtivas na formação social brasileira. O Rio Grande do Sul assumiu, neste todo, uma situação periférica dependente, na qual a própria indústria gaúcha nasceu. Os obstáculos e elementos facilitadores a esse processo industrial são basicamente resultado da atuação do capitalismo mundial. Os elementos internos da formação industrial gaúcha se restringem no nascimento de uma indústria incorporada ao modelo agropecuarista exportador com o envolvimento da dependência de mercados. Essa vinculação foi herdada pelo processo industrial, no seu primeiro momento, na região Pelotas-Rio Grande, caracterizado pela grande indústria voltada ao mercado nacional. Com a industrialização, num segundo momento, na região Porto Alegre-zona colonial, tem-se em si a base do processo indústria gaúcha, com alta diversificação e pequenas empresas: Um outro aspecto a ser considerado é o caráter artesanal do trabalhador na indústria de origem imigrante. Esse, juntamente com o próprio burguês industrial de capitais oriundos do comércio, com certos casos na região Porto Alegre-zona colonial de evolução do artesanato, também de origem imigrante, representavam o "novo" (a indústria) que se instalou ao lado do "velho" (a agropecuária). Essa nova situação levou o Estado gaúcho a dar certos benefícios isolados ao mesmo, mas não assumindo o processo industrial. Durante toda a República Velha, o Rio Grande do Sul se manteve como um Estado agropecuarista acrescido do novo, a indústria, incrementada pelos imigrantes. Dentro desse novo processo, a raiz determinada pelo segundo momento de industrialização na região de Porto Alegre e zona colonial se impõe decisivamente, com alta diversificação industrial e tendo apenas com a indústria têxtil um setor com traços fabris claramente definidos. 


\section{2 - A BURGUESIA INDUSTRIAL GAÜCHA NA REVOLUÇÃO DE 30}

\section{O fato histórico que faz com que inicie um novo periodo político na história brasileira é a Revolução de 30 . Conforme Boris Fausto:}

A Revolução de 30 pőe fim à hegemonia da burguesia do café, desenlace inscrito na própria forma de inserçao do Brasil, no sistema capitalista internacional, sem ser um produto mecânico da dependência externa. O episódio revolucionário expressa a necessidade de reajustar a estrutura do Pais, cujo funcionamento, voltado essencialmente para um único gênero de exportação, se torna cada vez mais precário 1.

Essa mexida na estrutura agroexportadora brasileira trouxe possibilidades (mesmo ilusórias) de oligarquias regionais aspirarem ao poder central do pais.

Como partiu da oligarquia regional gaúcha em si a iniciativa do movimento revolucionário, a burguesia industrial no Rio Grande do Sul levou os seus beneficios. Revendo as justificativas da criação do Centro da Indústria Fabril do Rio Grande do Sul, pode-se notar a sua direta vinculação com o movimento de 30 . Conforme o relatório:

Reconhecia-se a necessidade da existência de uma entidade juridica que, reunindo os representantes da industria, harmonizasse opiniōes divergentes, mas que visavam uma mesma finalidade, e, concentrando esforços dispersos, oreintasse-os, em uma ação uniforme, em benefício da classe, podendo, para defesa dos seus direitos, falar em nome da coletividade.

Reconhecia-se a vantagem que poderia trazer para a coletividade a orientaçăo, assim disciplinada e consciente, de uma entidade que estabelecesse um como traço de união entre os poderes públicos e a indústria, facilitando a esta os meios de tornar conhecida a sua opinião em relação aos problemas a serem resolvidos por aqueles e que encerrem matéria de interesse da classe

Ao mesmo tempo, uma agremiação nesses moldes, estabelecendo contato mais direto e mais assiduo com os poderes públicos, com maior facilidade tornaria conhecidas as necessidades da classe e poderia, também, fazer valer os seus direitos.

Foi quando irrompeu o movimento revolucionário de 1930 e, isolado, por conveniência da causa, o nosso Estado dos demais da federação, perturbou-se o funcionamento das indústrias, surgindo a ameaça da iminente e completa paralisação das suas atividades, que corporificou-se aquela idéia.

Utilizados, nessa ocasião, todos os meios de transportes nos serviços militares, mais premente tornou-se a crise que já se sentia entre as forças econômicas do Estado.

Além disso, a escassez ou mesmo falta de algumas matérias-primas que não podiam entrar no Rio Grande do Sul e a impossibilidade do escoamento da produçăo impunham uma medida enérgica e pronta.

E mais grave se tornava ainda o problema, pois o fechamento das fábricas viria complicar profundamente a situação em si bastante delicada em nosso Estado, no momento em que alguns estabelecimentos trabalhavam apenas de três a quatro dias por semana, pois ficariam completamente sem meios de subsistência, algumas dezenas de milhares de operários e suas respectivas familias

Ciente da ameaça que se avolumava, o Governo do Estado procurou concertar com os industriais o meio de evitar o colapso que se aproximava.

Por intermédio do sr. Major Alberto Bins, então Intendente desta Capital, reuniu os industriais no salăo nobre da Intendência, fazendo-lhes ver a necessidade de se unirem para enfrentar tal situaçăo, sendo, em consequeência e na mesma ocasião, fundado o Comitê Industrial, de caráter oficial, mas transitório, com o fim exclusivo de estudar e resolver os meios a serem postos em prática pelo Governo e pelos mesmos industriais, para minorar a consequeencia do mal, 
Dada a estreita relação desse Comitê Industrial, com a fundação do Centro da Indústria do Rio Grande do Sul e sendo interessante a sua ação num momento de tâo graves apreensōes, como foi aquele, julgamos năo ser de mais registrar aqui a sua atuação e a atividade que dispenderam os seus membros, serão para completa solução do problema, ao menos para contornar ou remediar os males que a todos ameaçavam 2 .

O Comitê Industrial, formando por A. J. Renner, Ernesto Neugebauer, Oscar Campani, João Wallig, Alberto Jung e Oscar Gertum, que serviu como grupo inicial na criação do Centro, teve toda a conjuntura surgida com a Revolução de 30 a seu favor. A sua preocupação girou, basicamente, em amparar os operários e evitar a paralisação completa das indústrias, mantendo no mínimo três dias de serviço por semana, com o objetivo de assegurar a subsistência dos operários. Para tanto, foi realizado um estudo de cada indústria em particular, através das seguintes informações:

Para firmar a diretriz a ser seguida, o Comitê dirigiu-se a todos os industriais, pedindo-lhes as seguintes informaçoes:

$1^{\circ}$ - Quantos operários tem?

$2^{\circ}-$ Qual a soma de sua folha de pagamento, ultimamente?

$3^{\circ}-$ Quantos dias trabalha atualmente por semana?

a) O trabalho é uniformemente dividido?

b) Há operários \{uja especialidade não permite reduçăo de dias de trabalho?

$4^{\circ}$ - Tem contas com o Governo Estadual e Municipal, de fornecimentos feitos antes do dia 3 de outubro do corrente ano?

A quanto montam?

$5^{\circ}$ - Fez fornecimentos em virtude de requisição dos mesmos Covernos, depois daquela data?

A quanto montam?

$6^{\circ}$ - Está trabalhando em artigos que o Governo pode precisar?

$7^{\circ}$ - Sua indústria está aparelhada durante um mês na proporção de três dias por semana?

Em caso negativo, qual o motivo que o impossibilitou de trabalhar?

$8^{\circ}$ - Pode e quer fazer warrantagem e quais os artigos que quer warrantar?

$9^{\circ}$ - Que e pode fazer distribuiçāo de gêneros alimenticios, em caso de faltar serviço aos seus empregados?

$10^{\circ}$ - Qual o número de operários que estão sujeitos a ficar sem trabalho e por conseguinte a necessitar de auxilio de mantimentos?

$11^{\circ}$ - Em caso de distribuição de gêneros alimenticios, em caso de faltar serviço aos seus empregados?

$11^{\circ}$ - Em caso de distribuição de gêneros alimenticios aos seus operários, quer $\mathrm{e}$ pode fazer em seu estabelecimento ou prefere adquirir e distribuir cautelas da Municipalidade aos mesmos, que poderão ir aos postos de Intendência?

$12^{\circ}$ - Dos materiais cuja venda, sem a respectiva licença, o Governo proibe, quais os que gasta e que quantidade precisa por mês? 3

Concluiu-se do estudo que o enfrentamento do impasse dependia, em grande parte, do pagamento pelo Governo gaúcho do valor das mercadorias requisitadas pelas autoridades revolucionárias. O Estado gaúcho auxiliou, evitando que as fábricas não fechassem suas portas e garantissem o ganha-pão dos operários. Inclusive, seguindo conselhos do próprio Comitê, nos estabelecimentos nos quais o trabalho era de todo impossível, os próprios industriais, espontaneamente, fizeram distribuição de alimentos, conforme o Relatório do Centro. Acrescenta o Relatório: 
(...) cessada, porém, a revolução, resistiu logo, a classe industrial, a falta de dinheiro para atender as necessidades do momento. Pouco a pouco, apesar dos efeitos da crise, a atividade industrial foi retornando à normalidade, suspendendo as medidas de emergências postas em prática (...) desta forma, e em razāo da boa vontade do Governo do Estado e dos esforços desinteressados e altruisticos de representantes da classe industrial, evitou-se que a falta de trabalho criasse uma série complicação à situação decorrente da revoluçáo e deixasse ao desamparo um elevado número de familias (...) No entanto, a situaçáo criada pelo movimento revolucionário para as industrias do Estado e principalmente desta capital, obrigando os industriais a se unirem num esforço conjunto para enfrentar a situação em que se encontravam, teve a vantagem de avivar a idéia que existia, de fundação de uma associação que permanentemente defendesse os interesses da classe (...) para defender e amparar as indüstrias em todas as emergências 4 .

Essas deliberações surgiram na reunião convocada pelo Comitê Industrial na sede da Sociedade de Banha Rio-grandense Ltda. a 22 de dezembro de 1930 , presidida por A. J. Renner. Dai, foi o próprio A. J. Renner que levou adiante a idéia da criação do Centro, sendo finalmente, em 19 de janeiro de 1931, realizada a primeira Assembléia Geral dos associados para discussão e aprovação dos estatutos, eleição e posse da primeira Diretoria efetiva, tendo como: Presidente - A. J. Renner; Vice-Presidente - Herbert Bier; $1^{\circ}$ Secretário - Dr. Aníbal di Primio Beck; $2^{\circ}$ Secretário - Oscar Campani; $1^{\circ}$ Tesoureiro - Frederico Casper; $2^{\circ}$ Tesoureiro - Herbert Müller. Por proposta de A. J. Renner, a assembléia resolveu conceder o título de Presidente Honorário ao Sr. Major Alberto Bins. Iniciou o Centro com 24 sócios.

Estes fatos que cercam a criação do Centro de Indústrias nos mostram o elemento facilitador que foi a conjuntura nacional. O próprio envolvimento do Estado gaúcho com a burguesia industrial, empenhado em auxiliar as indústrias enfraquecidas devido à Revolução, como pagamento posterior de requisições de Guerra através da Caixa Militar, estabeleceu um compromisso mais direto entre o Estado e a burguesia industrial. Conforme trecho da ata $n^{\circ} 1$ da reunião-almoço de 8 de dezembro de 1930:

Após a discussão de diversos assuntos de interesses fabril e industrial pelos as sociados presentes à reunião, e como ninguém mais desejasse usar da palavra, o $\mathrm{Sr}$. A. 1. Renner convida a todos para incorporados irem à presença do Exmo Sr. Gene ral Flores da Cunha, Interventor do Estado, a fim de apresentar a sua Excia. um memorial assinado pelo Comitê Industrial, solicitando a interferência de sua Excia. no sentido de ser reiniciado o pagamento das requisiçōes de guerra, unico meio dos in dustrialistas locais poderem continuar o trabalho das suas fábricas

Esse convite foi unanimente aceito, sendo encerrada a sessão e tendo os associados presentes dirigido-se todos ao Palácio do Coverno 5

A própria organização da classe industrial, fora os elementos facilitadores a nivel nacional através da criação do Ministério do Trabalho e da elaboração da legislação trabalhista, teve efeitos diretos da Revolução de 30. O Estado gaúcho precisou de indústrias. $\mathrm{E}$ os industriais buscaram o apoio do Estado recebendo beneficios exigidos. Assim, a burguesia industrial gaúcha entrou no reajuste da estrutura do país através da Revolução de 30.

3 - A ATIVIDADE EXPORTADORA: AGROPASTORIL E INDUSTRIAL NA TOTALIDADE GAUUCHA

Ao nivel de produção, no período 1930-1935 a atividade agricola somou 
$47,42 \%$, a pastoril $6,29 \%$ e a manufatura industrial $46,28 \%$ (inclusive de produtos agropecuários) do total (6). Entre os 15 produtos mais exportados de 1931-1935 em ordem decrescente, têm-se o charque, banha, arroz, couro, vinho, carne frigorificada, lãs, fumo em folha, feijấo, farinha de mandioca, cebola, sebo, madeiras, batata-inglesa e erva-mate (7). Observa-se que todos são produtos agropecuários. Quer dizer que a manufatura industrial acima é composta basicamente de produtos agropastoris. Tem-se então, no Rio Grande do Sul, uma economia predominantemente agropastoril com industrialização em boa escola dos mesmos.

Ao nível de comercialização, do total da produção gaúcha $33,43 \%$ foi exportada nos anos de 1930-1934. Dessa exportação, 64,96\% era dirigida ao mercado interno brasileiro e $30,54 \%$ para o exterior nos anos de 1930-1936 (8).

Tem-se no Rio Grande do Sul uma economia voltada ao mercado externo, principalmente ao mercado interno brasileiro. A participação dos artigos manufaturados nestas exportações é de apenas $10,14 \%$, somando os produtos agropastoris $89,86 \%$. Em contrapartida, o Rio Grande do Sul importou $61,39 \%$ de artigos manufaturados e $38,61 \%$ de outros produtos agropastoris (9).

Até aqui, tem-se um quadro bastante claro. O Rio Grande do Sul, na República Nova, é um Estado de produção essencialmente agropecuária e de exportação dos mesmos e importador de artigos manufaturados.

A partir dessa situação num estudo de caso, procura-se ver a função do porto de Santos como entreposto comercial. Esse porto intermediava, além de todos os produtos paulistas para o Rio Grande do Sul e importações para São Paulo de produtos gaúchos, também produtos estrangeiros para o Rio Grande do Sul. Valemo-nos para ver o comportamento dessa comercialização na década de 30 de dados de 1929-1930 e 1939-40 (10). Vê-se que, em 1929 e 1930, do total de exportações do porto de Santos para Estados brasileiros, 30,69\% (em valor) é exportado no ano de 1929 para o Rio Grande do Sul a $26,72 \%$ em 1930. Já em 1939-1940, essa exportação aumenta para $33,12 \%$ e $31,75 \%$. Deduz-se desse comportamento que há um aumento das importações pelo Rio Grande do Sul dos produtos paulistas. Por outro lado, São Paulo importou do Rio Grande do Sul, em 1929 (em valor), $18,46 \%$ e 23,28\% em 1930 do total de suas importaçōes. Já em 1939, São Paulo importou do Rio Grande do Sul $39,97 \%$ e em $194034,53 \%$ do total de suas importações dos Estados brasileiros. Conclui-se, daí, que igualmente São Paulo aumentou suas importações do Rio Grande do Sul no decorrer da década.

Entre os produtos estrangeiros industriais vindos por Santos para o Rio Grande do Sul, tem-se um média de $94,42 \%$ nos anos de 1929-1930 do todo das exportações, incluindo produtos animais e vegetais. A situação quase se repete com os produtos paulistas. Do total da exportação de São Paulo, dos seus produtos para o Rio Grande do Sul, 94,20\% são produtos industrializados, também numa média dos anos de 1929-1930. Essa situação reflete que o Rio Grande do Sul depende profundamente dos produtos industrializados paulistas no início da década.

Por outro lado, a importação por parte de São Paulo é basicamente de pro- 
dutos animais, com $45,94 \%$ das importações gaúchas, seguido de produtos industrializados $(29,24)$ e produtos vegetais $(24,25 \%)$, também numa média dos anos 1929-1930.

Deduz-se da análise desses dados que o Rio Grande do Sul depende industrialmente de São Paulo e exporta para o mesmo Estado produtos animais e agrícolas. A nível de produto, São Paulo intermeia comercialmente do exterior para o Rio Grande do Sul principalmente veículos,pertences e o respectivo combustivel. E de seus produtos exporta ao Rio Grande do Sul, principalmente, tecidos, armarinhos, linhas, etc. Na sua importação do Rio Grande do Sul, considerando o mercado paulista como um dos principais do país, o mesmo segue a tendência da globalidade das exportações gaúchas, recebendo produtos agropastoris, como a banha, cebolas, fumo, lã, etc. Os produtos industrializados gaúchos exportados pelo Rio Grande do Sul ao mercado paulista se restringem a conservas, cerveja, tecidos, etc. Em 1940, o quadro de exportação para o Rio Grande do Sul, além de tecidos, ferragens e cigarros, acrescenta mais papéis, couros e produtos farmacêuticos que não figuravam destacadamente em 1930 . E na importação tem-se a queda da banha, como principal importação para São Paulo em 1930, e a entrada do vinho entre os principais produtos de importação por São Paulo para o Rio Grande do Sul.

Todo esse quadro retrata a situação gaúcha de importador de produtos industriais manufaturados de São Paulo e exportador de matérias primas agropastoris.

Os dados analisados acima mostram a situação periférica do Rio Grande do Sul na República Nova, em relação ao centro brasileiro, no caso São Paulo. A economia gaúcha mantém a sua tradição histórica de exportador de produtos agropastoris, ficando a indústria manufatureira de lado, em segundo plano, da principal atividade econômica do Estado gaúcho.

A indústria manufatureira, alheia a este processo econômico, com baixa exportação e alta importação destes produtos, ainda se mantém na República Nova como um setor econômico emergente, com dificuldades de se manter ao lado da fluidez exportadora agropecuária e da fluidez da importação de produtos manufaturados, principalmente paulistas. Sobra a essa indústria um mercado interno gaúcho, que sofre, além dísto, a concorrência da entrada dos produtos paulistas. Pode-se notar a alta diversificação dos produtos paulistas no mercado gaúcho, conforme dados de importação acima. Daí as dificuldades da economia gaúcha não se darem apenas ao nível de manutenção de mercados externos, mas inclusive na manutenção do mercado interno, além de São Paulo produzir já em boa escala produtos básicos gaúchos, como o chárque, carne frigorificada, etc.

O Rio Grande do Sul mantém, na República Nova, a sua situação periférica em relação ao centro, que é São Paulo. Igualmente a sua situação subdesenvolvida é reforçada em função do caráter da atividade produtiva, de agropecuarista exportadora. A situação de dependência, que envolve, além do nivel econômico, o político, justifica-se pela frustração da oligarquia pecuarista gaúcha de assumir o poder central do país através da Revolução de 30 . A excessiva mercantilização da economia gaúcha, ainda na República Nova, resulta destas 
variáveis, dependendo cada vez mais do mundo industrializado e se mantendo como fornecedor de produtos de alimentação. Esse caráter da economia gaúcha envolve o seu processo de industrialização que, dentro da totalidade gaúcha, cumpre a missão específica de sócio menor do processo global. Essa missão, apesar dos elementos facilitadores depois da Revolução de 30 a nível nacional, paradoxalmente não refletiram compensatoriamente no Rio Grande do Sul, prevalecendo a raiz do processo histórico de economia periférica de características exportadoras.

Dentro dessa conjuntura, o processo industrial foi inserido. O predominio da economia agroexportadora periférica, tendo como elemento definidor o próprio mercado que lhe impunha a exportação de produtos alimentares e de matérias primas, principalmente para o mercado interno brasileiro, e a importação de produtos manufaturados, principalmente de São Paulo, traçavam as dificuldades ao processo de industrialização no Rio Grande do Sul ao nivel de relações externas.

Esse processo emergente (o industrial), ao lado do tradicional (agroexportador), encontra então o seu principal entrave nas raizes históricas herdadas desse último, calcado numa situação dependente periférica e de subdesenvolvimento.

\section{4 - O PROCESSO INDUSTRIAL EM SI}

No estudo da indústria na República Nova, uma das dificuldades surgidas girou em torno do estabelecimento de um universo industrial. Conforme Sérgio Silva:

No seio da própria indústria, deve-se fazer uma diferença entre unidades de produção tais como: o artesanato, a manufatura e a fábrica. As diferenças entre essas unidades de produçăo sâo fundamentais para o desenvolvimento do capitalismo.

A manufatura e a fábrica distinguem-se da empresa artesanal pelo número de trabalhadores que empregam. Nas duas primeiras, o número de trabalhadores é que sua susbsistência, assim como a expansão da empresa, não dependem mais diretamente do seu trabalho. Elas são todas empresas capitalistas. Por sua vez, a fábrica distingue-se da manufatura pela importância do capital que emprega; a importância do capital manifesta ao nivel do valor uma outra organizaçăo. É na fábrica que a separaçăo entre o trabalhador e os meios de produção - chave do sistema capitalista - torna-se uma realidade técnica.

Assim, về-se que as diferenças entre esses tipos de unidades de produçăo estão diretamente relacionados com a produção tipicamente capitalista. Quando falamos em industrialização, pensamos na passagem para formas de produção baseadas na fábrica, na mecanizaçăo e no crescimento da chamada grande indústria. E, nessa passagem, incluimos a manufatura como uma forma de transição historicamente determinada 11.

Valendo-se dessa colocação, tem-se no Rio Grande do Sul o critério usado pelo Centro da Indústria Fabril do Rio Grande do Sul para admissão de indústrias. Ele sugere uma separação entre manufaturas e fábricas. $\mathrm{O}$ artigo $6^{\circ}, \mathrm{I}$ e II, do anexo $n^{\circ} 13$ dos seus estatutos, fixa:

Artigo $6^{\circ}$ - Para ser sócio do Centro é necessário ter boa reputação e legalmente exercer a indústria fabril no Estado do Rio Grande do Sul, preenchen- 
do ainda uma das seguintes condições:

a) dar trabalho em seu estabelecimento, normalmente, em um só turno pelo menos a vinte e cinco (25) operários;

b) ter invertido capital que pelo seu vulto justifique a capacidade da sua indústria, cujo capital não poderá ser inferior a duzentos contos de réis (200.000\$000) (12).

Esta visão do momento histórico de análise, de selecionar indústrias, sugere usar o mesmo critério para delimitar a grande indústria manufatureira do Rio Grande do Sul. As outras inferiores a esse critério serão consideradas, neste trabalho, como a pequena indústria manufatureira.

\section{1 - A pequena indústria}

Considerando o processo industrial gaúcho em si, tem-se uma estrutura formada, no decorrer da República Velha, de características marcadamente de alta diversificação nas linhas de produção, com dificuldades na competição no mercado externo. Essas dificuldades decorrem da própria inserção numa economia agro-exportadora (que é dominante na formação social gaúcha), e da concorrência dos produtos manufaturados paulistas, cujo Estado se adiantou no processo de industrialização devido a transferência de capitais do café.

Então, o comportamento da indústria na República Nova, apesar do alento que significou a Revolução de 1930 , teve, numa comparação entre os anos de 1930-1931 e 1936-1937, quer dizer, início e fim da República Nova, período em questão, uma tendência que não alterou a estrutura industrial estabelecida anteriormente.

Numa observação do crescimento físico da produção industrial nesse período, pode-se observar que os setores industriais que mais cresceram foram: armas e munições; tecidos em quilo; queijos e requeijões; brinquedos, instrumentos de música; artefatos; tecidos e peles; papel e artefatos; perfumarias; etc. (13). Pode-se notar que os setores que mais cresceram não constam entre as principais exportações gaúchas. Quer dizer, apesar do seu crescimento no todo da economia gaúcha, não conseguiu se impor, ficando esse crescimento mais vinculado ao crescimento do mercado interno gaúcho.

O objetivo de traçar o quadro da pequena indústria manufatureira nos levou a buscar os setores industriais (com o seu número de fábricas) e o seu respectivo número de operários, visando a detectar o grau de diversificação da mesma.

Nos anos 1935-1936, tem-se inicialmente as indústrias com registro gratuito, não sujeitos ao imposto de consumo. Essas indústrias somam do total do universo considerado $41,96 \%$. Ao lado dela, têm-se as indústrias com até seis operários, que somam um total de $45,03 \%$. Pode-se ver que a soma dos dois perfaz $86,99 \%$ do total, sobrando para as indústrias com mais de seis operários apenas $13,01 \%$.

Um outro aspecto significativo é o predominio da indústria de bebidas em 
relação aos outros setores industriais de $48,26 \%$ em termos de número de fábricas. Esse predomínio se dá tanto nas indústrias com registro gratuito, como nas de até seis operários, com mais de seis até 12 operários e com mais de 12 operários ou força motriz equivalente. Quer dizer, trata-se do setor industrial de maior número de fábricas, sobrando para todos os outros setores um pouco mais da metade, no caso $51,74 \%$.

Considerando cada setor em si, pode-se ressaltar a tendência já destacada anteriormente, com a maioria das indústrias possuindo até seis operários. As indústrias acima de seis operários somam apenas $13,01 \%$. Aqui se pode ressaltar um aspecto fundamental: apenas a indústria têxtil está entre as indústrias acima de 12 operários, com $59,26 \%$. Isso é significativo porque, basicamente, em todos os outros setores nenhum deles tem predominio nessa classificação de mais de 12 operários ou força motriz equivalente. Pode-se deduzir disso que,ao lado da indústria agropastoril, apenas a indústria têxtil pode ser classificada como a grande indústria. As outras continuam predominantemente pequenas, tendo todos os setores industriais, na sua maioria, menos de 12 operários. Isso reforça o caráter altamente diversificador, ainda na República Nova, da indústria gaúcha de que sua mão-de-obra ainda possui traços artesanais bastante acentuados (14).

Tem-se dessas considerações acima o quadro da nossa pequena indústria, que, na sua maioria, é de até seis operários e com registro gratuito. $\mathrm{O}$ crescimento da mesma se evidenciou nessas indústrias, ficando a mesma em função do mercado interno gaúcho, no crescimento da própria diversificação industrial. Apenas a indústria de tecidos se manteve como indústria, predominantemente com mais de 12 operários.

\section{$4.2-A$ grande indústria}

Na consideração do universo das indústrias com mais de 12 operários ou força motriz equivalente, pode-se fazer a separação do universo das indústrias associadas ao Centro da Indústria Fabril do Rio Grande do sul. O critério de admissão exigia ter mais de 25 operários e/ou capital superior a $200.000 \$ 000$. Tem-se então, no periodo 1933-1937, o percentual de participação dessas indústrias, no total do universo das indústrias gaúchas. Apenas $1,50 \%$, na média do total, restringem-se ao universo da grande indústria (15).

Num detalhamento desse universo da grande indústria, tem-se desde a fundação do Centro das Indústrias até o ano de 1937, numa média destes anos, $66,98 \%$ das mesmas localizadas em Porto Alegre e $33,02 \%$ no interior.

Do interior, o municipio que mais possui indústrias associadas no final do periodo é São Leopoldo, seguido por Pelotas, Rio Grande, Caxias do Sul e Novo Hamburgo. No início do periodo, predominavam Pelotas e Rio Grande.

Nota-se, dessa ampliação do universo, que a região colonial adquiria força em relação à indústria de Pelotas e Rio Grande, ficando Porto Alegre estacionada.

Tem-se desse processo induștrial a reafirmação do caráter do mesmo, for- 
mado no inicio do século. Os seus setores, que poderiam ampliar as suas fronteiras de mercado, entravavam nos obstáculos da estrutura agroexportadora gaúcha e na concorrência dos produtos paulistas, além de não ter condições de suplantar o seu próprio obstáculo, de estrutura produtiva muito diversificada e sem produtos competitivos para o mercado externo, tanto nacional como estrangeiro.

\section{5 - CONCLUSÃO}

Em si, a indústria já nasceu com os seus próprios obstáculos. Os mesmos, ao nivel externo no seu momento de gestação, devem ser buscados, a nivel nacional, no início tardio, embora contemporâneo, do processo em relação a São Paulo. Além desse aspecto, o próprio envolvimento que o modelo agroexportador trouxe à indústria foi decisivo, colocando o mesmo como processo secundário no todo da formação social gaúcha. Ao nível interno, a agropecuária entravou o processo emergente, trazendo-lhe obstáculos tanto ao nivel de forças produfivas como relações de produção. O próprio Estado gaúcho, controlado pela oligarquia agropecuarista, apenas deu benefícios isolados à indústria, mantendo-se a mesma ainda durante toda a República Velha, com traços artesanais bastante acentuados e altamente diversificada com traço fabril basicamente só na indústria têxtil. Já na República Nova, a herança do processo vindo da República Velha não alterou o panorama do quadro industrial. Com a Revolução de 30 , a burguesia industrial teve, de certa maneira, um respiradouro, podendo ampliar o seu espaço na luta pela industrialização e seus interesses. Mas o mesmo em termos qualitativos não se evidenciou. Apenas esse setor social se organizou em torno do Centro da Indústria Fabril do Rio Grande do Sul, amparando os seus interesses em relação ao Estado e à legislação trabalhista em estudo e discussão.

No todo da formação social gaúcha já na República Nova, a indústria se manteve com destaque na transformação de produtos agropecuários, sendo a área manufatureira a menor produção ao lado da produção agrícola e pastoril. Sendo o Rio Grande do Sul, tradicionalmente, um Estado exportador de produtods agrícolas e pecuários, na República Nova esse caráter se reafirma, com a exportação de produtos de alimentação, basicamente para o mercado interno nacional. Em contrapartida, o Rio Grande do Sul se manteve como importador de produtos manufaturados, principalmente de São Paulo.

Considerando o processo industrial em si, o mesmo manteve o processo herdado da República Velha. Basicamente, todas as indústrias podem ser classificadas como a pequena indústria, menos o setor têxtil. Reafirma-se aqui o caráter altamente diversificador da indústria gaúcha. A grande indústria (com mais de 25 operários ou capital de $200.000 \$ 000$ ), ao lado destas fabriquetas, comporta, na média, apenas $1,50 \%$ do total das indústrias gaúchas.

E importante frisar que a indústria voltada ao mercado interno gaúcho realmente se mantém, mas a concorrência de produtos paulistas no mesmo mercado é bastante acentuada, através do quadro de exportações de São Paulo para o Rio de Grande do Sul. A indústria exportadora do Rio Grande do Sul, que se restringia principalmente aos produtos agropecuários, teve o seu alento 
na matéria prima local. Apenas a indústria têxtil, que buscava a mesma de fora, conseguia manter, embora com dificuldades, a sua competitividade no mercado externo ao lado da indústria agropecuária. A dominação da indústria manufatureira paulista a nível nacional impõe ao processo econômico gaúcho o enraizamento da situação periférica. A indústria gaúcha, como secundária, dentro do seu processo global / segue a tendência da economia agroexportadora do Rio Grande do Sul de características dependentes e subalterna ao nível político em relação ao centro paulista.

A indústria gaúcha, basicamente, configurou-se em torno do mercado local através da pequena indústria, e essas independem da matéria-prima local ou importadora. A necessidade comercial nacional apenas está ligada à grande indústria exportadora de produtos agropecuários e a têxtil.

No envolvimento do Estado gaúcho com o processo industrial, tem-se um certo grau de insatisfação por parte da burguesia industrial gaúcha, principalmente em função do imposto de exportação, controlado pelo Estado gaúcho. A questão da tecnologia e matéria-prima, ligada ao Governo Federal, era tida pelo Centro das Indústrias mais ao nível de discussão e negociação de prováveis beneficios. Mas, tranqüilamente, a burguesia industrial gaúcha é sócio menos do Estado, no qual predomina o setor agropecuarista.

Pode-se concluir que a burguesia industrial gaúcha, na República Nova, teve uma ampliação no universo de sua atuação, através da Revolução de 30 e conseqüente criação do Centro da Indústria Fabril do Rio Grande do Sul, em relação à República Velha. Agora, na verdade, essa ampliação não refletiu em mudanças no processo industrial gaúcho, ao nível de forças produtivas.

\section{NOTAS}

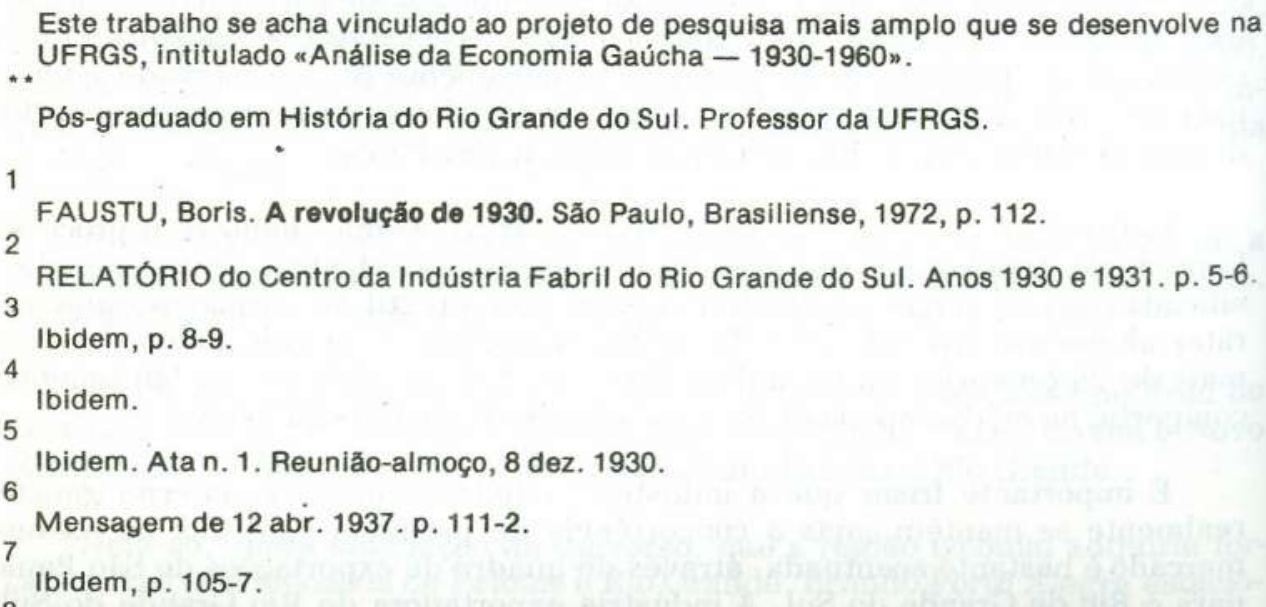

Mensagem de 12 abr. 1937 e Sinopse Estatistica. 
9

10

Sinopse Estatistica.

Relatórios de importação e exportação pelo porto de Santos.

11

Silva, Sérgio. Expansão cafeeira e origem da indústria no Brasil. São Paulo, Alfa Omega, 1976. p. 82.

12

RELATÓRIO do Centro da Indústria Fabril do Rio Grande do Sul. Anos 1930 e 1931. p.26. 13

Anuário Estatistico do Estado do Rio Grande do Sul.

14

Sinopse Estatistica do Estado do Rio Grande do Sul.

15

Relatórios do CIERGS e Sinopse Estatistica do Estado do Rio Grande do Sul.

\section{BIBLIOGRAFIA}

CASTRO, Antônio Barros de. Sete ensaios sobre a economia brasileira. 2. ed. Rio de Janeiro, Forense, 1971. vo. 2.

CANO, Wilson. Raizes da concentração industrial em São Paulo. São Paulo, DIFEL, 1977.

CARDOSO, Fernando Henrique \& FALETTO, Enzo. Dependência e desenvolvimento na América Latina. Rio de Janeiro, Zahar, 1975.

FAUSTO, Boris. A Revolução de 1930. 2.ed. São Paulo, Brasiliense, 1972.

HOBSBAWN, E.J. Da revolução industrial inglesa ao imperialismo. Rio de Janeiro, Forense Universitária, 1978.

MULLER, Geraldo. Periferia e dependência nacional. São Paulo, USP, 1972, (tese de mestrado em Sociologia).

PESAVENTO, Sandra Jatahy. Charqueadas, frigorificos e criadores: um estudo sobre a República Velha Gaúcha. Porto Alegre, PUC-RS, 1978. (Tese de mestrado)

PETERSEN, Silvia. El proletariado urbano en Rio Grande do Sul; 1888-1919. México, UNAM, 1977. (Tese de mestrado)

REICHEL, Heloisa Jochims. A indústria têxtil do Rio Grande do Sul; 1910-1930. Porto Alegre, PUC-RS, 1978. (Tese de Mestrado).

ROCHE, Jean. A colonização alemã no Rio Grande do Sul. Porto Alegre, Globo, 1969.

SILVA, Sérgio. Expansão cafeeira e origem da indústria no Brasil. São Paulo, Alfa-Omega, 1976 .

SINGER, Paul. Desenvolvimento econômico e evolução urbana. São Paulo, Ed. Nacional, 1977.

TEJO, Limeira. A indústria rio-grandense em funçāo de economia nacional. In: Diretoria Geral de Estatistica. Estatistica industrial do Rio Grande do Sul. Porto Alegre, Globo,1939.

\section{MENSAGENS}

MENSAGEM à Assembléia Legislativa do Estado do Rio Grande do Sul, pelo Dr. Darcy Azambuja, Secretário dos Negócios do Interior, no exercício do cargo de Governador do Estado. Anos 1935-1937.

ANUARIOS

ANUÁRIO Estatistico do Estado do Rio Grande do Sul. Repartição de Estatistica, Porto Alegre.

SINOPSE Estatistica do Estado do Rio Grande do Sul. Repartição de Estatistica, Porto Alegre. 
RELATORIOS do Centro da Indústria Fabril do Estado do Rio Grande do Sul. Anos de 1930-1931, 1931-1932, 1932-1933, 1933-1934, 1934-1935, 1935-1936, 1936-1937.

AVULSOS

RELATÓRIOS de Exportaçăo e Importação pelo Porto de Santos. 